\title{
Molecular Characterization of Fusarium oxysporum G30 Isolated from Vegetable Wastes in Imphal, Northeast India
}

\author{
Gehamanjuri Laimayum SHARMA ${ }^{1 *}$, Pinokiyo ATHOKPAM², \\ Bijaya Devi THONGATABAM ${ }^{3}$ \\ ${ }^{1}$ Manipur University, Department of Life Sciences, Canchipur, Imphal-03, India; geha09@gmail.com (*correspondingauthor) \\ ${ }^{2}$ Dhanamanjuri College of Science, Department of Botany, Imphal-01, India; pinkiathokpam@gmail.com \\ ${ }^{3}$ University of Mysore, Department of Studies in Zoology, Karnataka, India; bijaya.th@yahoo.co.in
}

\begin{abstract}
A new strain of Fusarium oxysporum (Schl.) emend. Synder \& Hansen, viz. Fusarium oxysporum G30, is reported from seven different decomposing vegetable wastes and a mixture of the same in equal proportions, in Imphal, Northeast India. This strain was isolated by surface sterilization technique, followed by re-culturing till pure culture was obtained. The pure culture was characterised morphologically based on the colony features: colour, texture, colony diameter; conidial features: macro and microconidial shape, size, septation, presence of chlamydospores and foot-shaped basal cells. The strain was also identified at molecular level by partial sequencing using universal primers, ITS 4 and ITS5. The ITS data reveals that isolated culture (F. oxysporum G30) match the existing isolates in Gen Bank (Gen Bank accession No. GQ497156.1) by 99\% and it has got a code segment particular to this strain. This strain showed ubiquitous nature with mean percent frequency of occurrence ranging from 39.5 to $68 \%$ at various stages of decomposition of the selected vegetable wastes.
\end{abstract}

Keywords: complex, decomposition, frequency of occurrence, Fusarium oxysporum species complex, microbial growth, new strain, vegetable waste management

\section{Introduction}

Fusarium oxysporum (Schl.) emend. Synder \& Hansen is an ubiquitous saprophyte found predominantly in the environment. This species has been reported to be responsible for a number of diseases in plants. F. oxysporum has been assigned as the most economically important species of the genus because of the numerous host range and the level of loss caused as a result of their infection in plants. Vegetable wastes which contribute 50-60 t/day of municipal solid wastes in Imphal (Anonymous, 2009) are known to be good supporters of microbial growth, especially of fungi, during the decay stages. Recent studies (Sharma and Pandey, 2012) reveal that this species occurs in maximum population in decaying vegetable wastes. Identifying this particular strain at molecular level will be useful for formulating effective biological treatment of vegetable wastes which have already become a problem for dumping in city areas. Such beneficial application of this fungus has been given less attention so far. Therefore, in the present study, the most common $F$. oxysporum strain, having the highest frequency of occurrence in decaying vegetable wastes, have been isolated and characterized at molecular level.

\section{Materials and methods}

\section{Study materials}

Selected vegetable wastes, namely, peels of Euryale ferox
Salisb. (Nymphaceae), Phaseolus sp. (Fabaceae), Solanum tuberosum Linn. (Solanaceae), Sechium edule Sw. (Cucurbitaceae), petioles of Brassica oleracea Linn. botrytis (Brassicaceae), pseudostem of Musa paradisiaca Linn. (Musaceae), sheaths of young edible shoots of Bambusa arundinaceae Willd. (Poaceae) and a mixture of the vegetable wastes in equal proportions were used as the study materials.

\section{Decomposition of vegetable wastes}

Decomposition studies of vegetable wastes were carried out both in litter bags by following nylon mesh bag technique (Bocock et al., 1960), as well as in experimental pots. Five gm air-dried vegetable wastes in each nylon net bag $(10 \times 15 \mathrm{~cm} ; 1$ $\mathrm{mm}$ mesh size) separately for each of the eight samples were randomly placed on soil surface in the experimental site located in the Department of Life Sciences, Manipur University. For each decomposing vegetable wastes at least three bags were recovered at monthly interval for a period of seven months (November-June) and brought to the laboratory in sterile polythene bags where the samples of each bag were brushed carefully to remove the adhering soil particles for the isolation of fungi. Similarly, $5 \mathrm{gm}$ air-dried sample were also allowed to decompose in plastic pots placed in tin roofed experimental shade adjacent to the experimental plot. Sterilized water was sprayed at 4 days interval $(1 \mathrm{ml} /$ pot $)$. As in the above case, contents of three pots for each sample were recovered at monthly interval for the isolation of fungi. 


\section{Isolation offungi}

The technique of surface sterilization using $15 \% \mathrm{H}_{2} \mathrm{O}_{2}$ and $70 \%$ Ethanol (Kinkel and Andrews, 1988) was employed for the isolation of fungi inhabiting the decomposing of vegetable wastes. Bits of samples $\left(3 \times 3 \mathrm{~mm}^{2}\right)$ were cut using sterilized scissors, immersed in $70 \%$ ethanol for 1 minute. These were then transferred to $15 \% \mathrm{H}_{2} \mathrm{O}_{2}$ for 1 minute and again to $70 \%$ ethanol for 1 minute, followed by washing with changes of sterilized distilled $\mathrm{H}_{2} \mathrm{O}$ for 5 minutes and air-dried in-between folds of sterilized blotting paper for 30 minutes. Five surface sterilized samples bits were then placed equidistant in each Petri dish containing $20 \mathrm{ml}$ PDA medium supplemented with streptomycin $(100 \mathrm{mg} / \mathrm{l})$. The plates were incubated at $25 \pm 1{ }^{\circ} \mathrm{C}$ for 7 days and fungal colonies developing on the bits were purified to identify and isolate $F$. oxysporum present. Three replicates were maintained in each case.

\section{Morphological characterization}

The isolated strain (Fusarium oxysporum G30) was morphologically characterized on the basis of colony features: colour, texture, colony diameter; conidial features: macro and microconidial shape, size, septation, presence of chlamydospores and foot-shaped basal cells by plating the pure culture of the fungus on three different media: (i) Potato Dextrose Agar (PDA) [Potato (peeled) $200 \mathrm{~g}$; Dextrose $20 \mathrm{~g}$; Agar $20 \mathrm{~g}$; Distilled $\mathrm{H}_{2} \mathrm{O}$ 1L]; (ii) Czapek's Dox + Yeast extract agar (CYA) [Sucrose $30 \mathrm{~g} ; \mathrm{NaNO}_{3} 2 \mathrm{~g} ; \mathrm{K}_{2} \mathrm{HPO}_{4} 1 \mathrm{~g} ; \mathrm{MgSO}_{4}+\mathrm{H}_{2} \mathrm{O}$ $0.5 \mathrm{~g} ; \mathrm{KCl} 0.5 \mathrm{~g} ; \mathrm{FeSO}_{4}+7 \mathrm{H}_{2} \mathrm{O} 0.01 \mathrm{~g}$; Agar $15 \mathrm{~g}$; Distilled $\left.\mathrm{H}_{2} \mathrm{O} 1 \mathrm{~L}\right]$ (Onions et al., 1981) and (iii) Lignocellulose Agar (LCA) [Glucose $1 \mathrm{~g} ; \mathrm{KH}_{2} \mathrm{PO}_{4} 1 \mathrm{~g} ; \mathrm{MgSO}_{4}, 7 \mathrm{H}_{2} \mathrm{O} 0.2 \mathrm{~g}$; KCl 0.2 g; $\mathrm{NaNO}_{3} 2 \mathrm{~g}$; Yeast Extract $0.2 \mathrm{~g}$; Agar $13 \mathrm{~g}$; Distilled $\mathrm{H}_{2} \mathrm{O} 1 \mathrm{~L}$ ] (Miura and Kudo, 1970). The pH of the test media was maintained at 5.5 being optimal for the growth and sporulation for majority of fungi. The Petri dishes were then incubated for 7 days at $25 \pm 1{ }^{\circ} \mathrm{C}$ in BOD incubator and the morphological characterization of the fungus was done by consulting standard literatures viz., Leslie and Summerell (2006) and Watanabe (2002) and confirmation of the culture identity was done at NFCCI (National Fungal Culture Collection of India), ARI, Pune, India (Accn. No. NFCCI 2065).

\section{Molecular characterization}

Molecular characterization of the culture isolate was performed at NFCCI, ARI, Pune by partial sequencing (ITS).

Genomic DNA was isolated in pure form from the culture. Nearly $500 \mathrm{dp}$ rDNA fragments were successfully amplified using universal primers-ITS4 (5'TCC TCC GCT TAT TGA TAT GC3') and ITS5 (5'GGA AGT AAA AGT CGT AAC AAG G3'). The sequencing PCR was set up with ABI-BigDye Terminator v3.1 Cycle Sequencing Kit (Part No. 4337455). PCR reaction was performed in a $25 \mu \mathrm{L}$ volume containing $10 \mathrm{X}$ PCR buffer, $200 \mathrm{mM}$ dNTP, $1 \mathrm{U}$ Taq polymerase, $10 \mathrm{pM}$ of each primers and 10 ng genomic DNA. While the amplification cycle consisted of an initial denaturation step of $95^{\circ} \mathrm{C}$ for 5 mins, followed by 30 cycles of (a) denaturation $\left(95^{\circ} \mathrm{C}\right.$ for 1 min), (b) annealing $\left(56^{\circ} \mathrm{C}\right.$ for $\left.1 \mathrm{~min}\right)$ and (c) extension $(72$ ${ }^{\circ} \mathrm{C}$ for $1 \mathrm{~min}$ ) further followed by a final extension step of 10 mins at $72{ }^{\circ} \mathrm{C}$. The sequence data was aligned with publically available sequences and analyzed to reach identity (Table 1).
Table 1.List of reference cultures of Fusarium oxysporum in Gen Bank

\begin{tabular}{llc}
\hline \multicolumn{1}{c}{ Accession } & \multicolumn{1}{c}{ Description } & $\begin{array}{c}\text { Max. } \\
\text { ident. }\end{array}$ \\
\hline GQ497156.1 & Fusariumoxysporum strain KKK19 & $99 \%$ \\
FJ158124.1 & Fusarium oxysporum f.sp.gladioli isolateUAS007 & $99 \%$ \\
FJ158128.1 & Fusarium sp.UAS011 & $99 \%$ \\
EU849584.1 & Fusarium oxyspormm f.sp.vasinfectumstrain Anyang City & $99 \%$ \\
EU750682.1 & Fusarium sp.14018 & $99 \%$ \\
\hline
\end{tabular}

\section{Data analysis}

Percent frequency of occurrence was calculated by the formula:

Frequency of occurrence $(\%)=($ Number of sample bits on which fungal species occurred/total number of bits observed) $\times 100$.

\section{Results and discussions}

In both decomposition studies a particular isolate of Fusarium oxysporum G30 was obtained from all the study samples throughout the study period with mean percent frequency of occurrence (F.O. \%) ranging from 39.5\% ( $M$. paradisiaca) to $68.0 \%$ (B. arundinaceae) in litter bag decomposition and $44.0 \%$ (B. arundinaceae) to $63.5 \%$ (mixed sample) in pot decomposition (Fig. 1). This result is another evidence to show the ubiquitous nature of $F$. oxysporum. Earlier, ubiquitous nature of $F$. oxysporum was reported by Sharma et al. (2011) while working on the diversity of microfungi associated with surface soil and decaying leaf litter of Quercus serrata. It has also been reported that $F$. oxysporum is the most widely dispersed Fusarium species and can be recovered from most soils - arctic, tropical or desert and cultivated or not (Leslie and Summerell, 2006). In fact, the near ubiquity of this fungus in soil worldwide has led to its inclusion in what has been termed the global mycoflora (Gordon and Martyn, 1997).

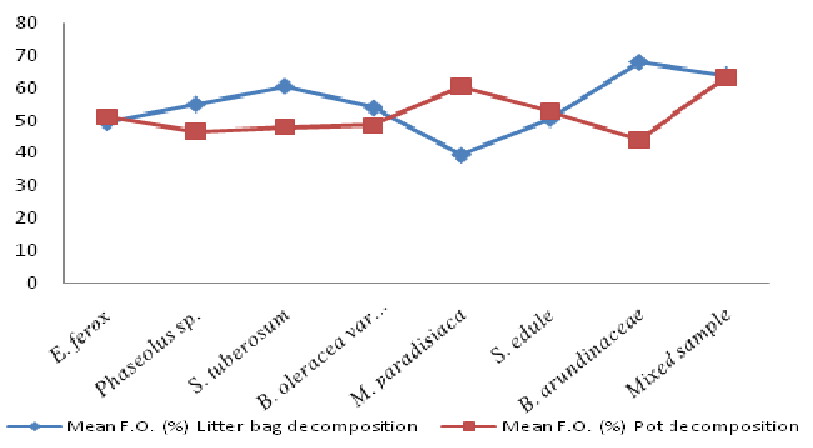

Fig. 1. Mean F.O. (\%) of Fusarium oxysporum G30 in decomposing vegetable wastes

\section{Morphological characterization}

Culture media differentially influence the growth, colony characters and sporulation of fungi (Sharma and Pandey, 2010) hence use of more than one culture media has been recommended for morphological characterization of this fungi also. Seven days old colonies (Fig. 2a) of $F$. oxysporum G30 on PDA measured $52.0 \pm 3.1 \mathrm{~mm}$ in diameter, floccose, magenta pink with concentric zones of dark and light reddish colouration; reverse magenta pink turning violet with age. Colonies on CYA measured $85.7 \pm 0.3 \mathrm{~mm}$ in diam., white, 
186

lacking zonations; reverse colourless, while colonies on LCA exhibited $79.7 \pm 0.3 \mathrm{~mm}$ diam. in growth, light cottony in texture, hyaline; reverse colourless after seven days of incubation. Microconidia and macroconidia were produced in all three culture media. Microconidia 1 to 2 celled, hyaline, fusiform to kidney shaped, produced singly from the tips of phialides, 0Septate 4-14 × 2-4 $\mu \mathrm{m}, 1$-Septate 9-33 × 2-5 $\mu \mathrm{m}$. Macroconidia slightly curved usually with three to five septa, rarely more; no foot-shaped basal cells observed, 3-Septate $2054 \times 2$ - 5 um, 5Septate $30-65 \times 3-6 \mu \mathrm{m}$. Chlamydospores present, abundant in older cultures, terminal and intercalary, single in majority of the cases measuring $10-15 \mu \mathrm{m}$ in diameter (Fig. 2b).

\section{Molecular characterization}

Morphological characterization alone is not enough as genetic information is not provided for identification of a species since the process is emphasized on differences of the morphological features which could readily be altered by environmental and cultural factors (Edel et al., 1995). In fact, fungal taxonomy is in a state of reflux because of the recent researches based on molecular approaches. Despite of the advancements and their considerable value, molecular approaches to fungal identification still remains

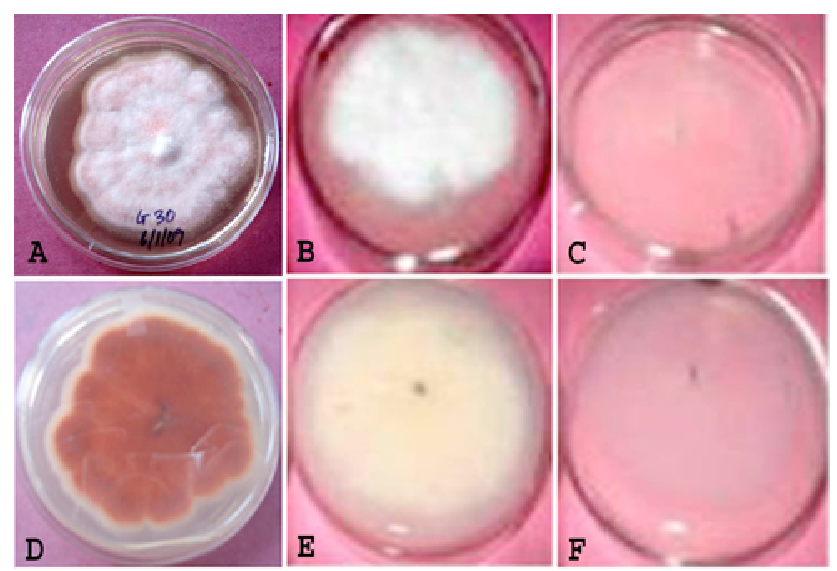

Fig. 2a. A. Fusarium oxysporum G30 on PDA media; B. Fusarium oxysporum G30 on CYA media; C. Fusarium oxysporum G30 on LCA media; D. Fusarium oxysporum G30 on PDA media (Reverse); E. Fusarium oxysporum G30 on CYA media (Reverse); F. Fusarium oxysporum G30 on LCA media (Reverse).

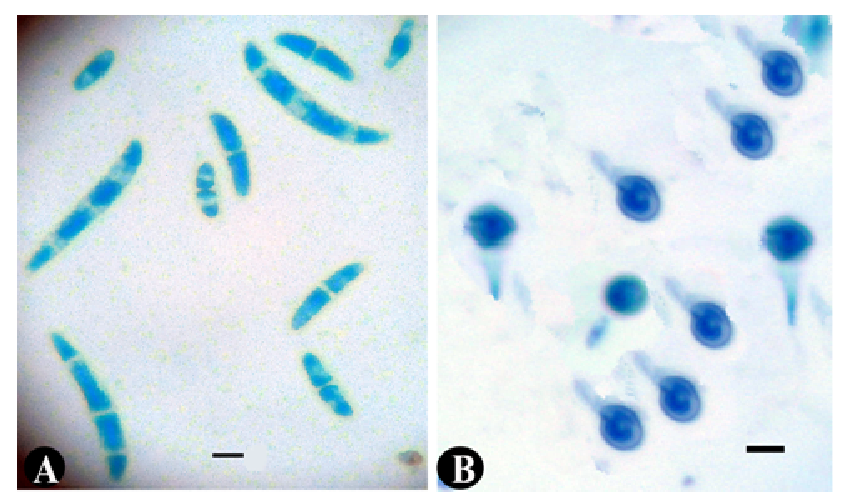

Fig. 2b. Fusarium oxysorum G30 (Scale $=10 \mu \mathrm{m})$ : A. Macro- and microspores; B. Chlamydospores

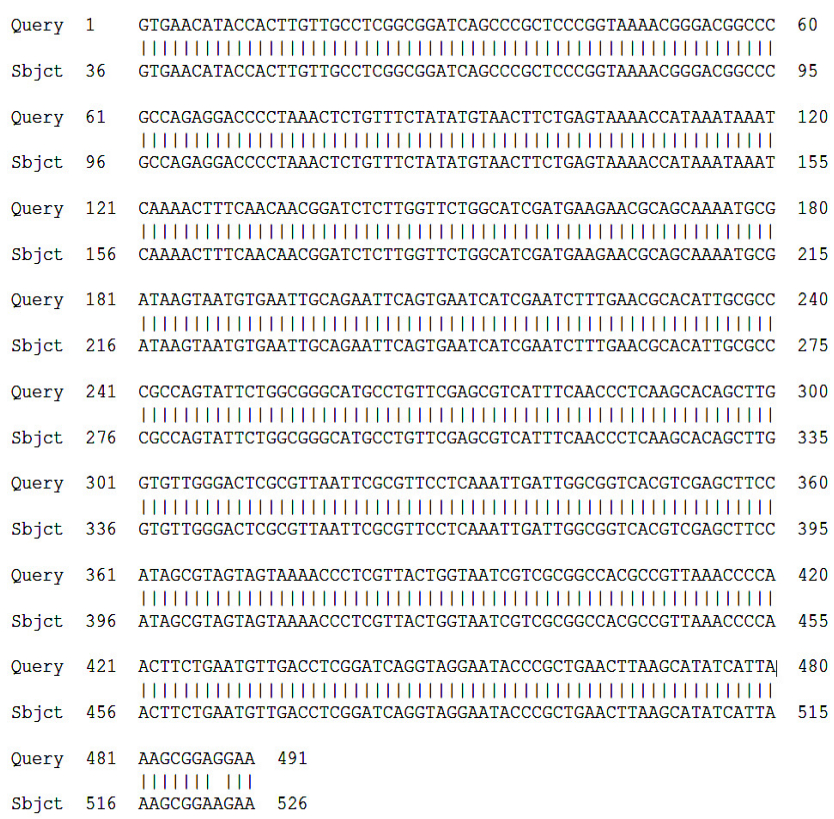

Fig. 3. Sequence analysis ( 491 bases) with (NCBI sequence Accession GQ497156.1)/G30 Sequences producing significant alignments

untouched in Northeastern region of India, which forms an important portion of the Indo-Burma biodiversity hotspots (Pawar et al., 2007). On molecular characterization this particular strain, Fusarium oxysporum G30, has got the following characters compared to other already defined isolates available in the Gen Bank database (Fig. 3).

The ITS data reveals that the isolated culture $F$. oxysporum G30 match the existing isolates in Gen Bank (Gen Bank accession No. GQ497156.1) by 99\% and has got a code segment in the Quary 481 to 491 of the sequence which is particular to this strain (Fig. 3). Fusarium oxysporum is a species complex consisting of morphologically indistinguishable strains. Therefore, molecular identification will serve the gene level documentation of this strain. In India, about 320 million tonnes of agricultural wastes are generated annually (Suthur et al., 2005) of which vegetable wastes alone is in major proportion. These vegetable wastes are either burnt or dumped elsewhere causing environmental pollution. Biological treatment of these wastes appears to be cost effective and carry a less negative environmental impact (Paraskeva and Diamodopoulos, 2006). The filamentous fungus, Fusarium oxysporum has attracted a lot of scientific interest due to its ability to produce lignocellulolytic enzymes which are required for degradation of the lignin and cellulose that form the main components of such wastes. Infact, Fusarium oxysporum is one of the most powerful lignin degraders isolated during a screening of lignolytic microorganisms in forest soil (Rodriguez et al., 1996). In this connection, the present strain identified might have potential significance in biodegradation with the following properties: high F.O. percent $(63.5 \%)$ in mixed vegetable in pot, ubiquitous nature of the strain for universal use and ability to grow in different media. Future detailed investigation may be carried out on assessing the 
biodegradability of this fungal strain in terms of weight loss and lignocellulose contents.

\section{Conclusions}

Morphologically this particular strain of Fusarium oxysporum G30 is hardly distinguishable from the other known strains viz. Fusarium oxysporum strain KKK 19 (GQ497156.1), Fusarium oxysporum f. sp. gladioli isolate UAS007 (FJ158124.1), Fusarium sp. UAS011 (FJ158128.1), Fusarium oxysporum f. sp. vasinfectum strain Anyang City (EU849584.1) and Fusarium sp. 14018 (EU750682.1). However, molecular identification of this particular strain showed $99 \%$ sequence similarity with the above mentioned known strains. The difference lies in Quary 481 to 491 of the sequence. Thus, the present strain is a distinct strain of Fusarium oxysporum and reported for the first time as a new strain.

\section{Acknowledgements}

The authors are thankful to the Mycology and Plant Pathology group, Agharkar Research Institute, Pune, India for confirmation and identification of the fungal strain. One of the authors, Gehamanjuri SHARMA Laimayum, thankfully acknowledge the Department of Science and Technology, New Delhi, India for financial assistance through Woman Scientists Scheme (SR/WOS-A/LS-57/2008 dated 08/09/2008).

\section{References}

Anonymous (2009). http://manipur.gov.in/IMC/CDP_Imphal.pdf.

Bocock KL, Gilbert O, Capstick CK, Twinn DC, Waid JS, Woodman MJ (1960). Changes in leaf litter when placed on the surface of soils with contrasting humus types. Journal of Soil Science 11(1):1-9.

Edel V, Steinberg C, Avelange I, Laguerre G, Alabouvette C (1995). Comparison of three molecular methods for the characterization of Fusarium oxysporum strains. Phytopathology 85(5):579-585.

Gordon TR, Martyn RD (1997). The evolutionary Biology of Fusarium oxysporum. Annu Rev Phytopathol 35:111-128.

Kinkel LL, Andrews JH (1988). Disinfestation of living leaves by hydrogen peroxide. Transaction of the British mycological Society 91(3):523-528.

Leslie JF, Summerell BA (2006). The Fusarium Laboratory Manual. Blackwell Publishing, Oxford, USA pp 212.

Miura K, Kudo MY (1970). An agar-medium for aquatic hyphomycetes. Trans Mycol Soc Jpn 11:116-118.

Onions AHS, Allsopp D, Eggins HOW (1981). Smith's introduction to industrial mycology. 7th Edition, Edward Arnold, London pp 372.

Paraskeva P, Diamadopoulos E (2006). Technologies for olive mill wastewater (OMW) treatment: a review. Journal of Chemical Technology and Biotechnology 81(9):14751485.

Pawar SS, Birand AC, Ahmed MF, Sengupta S, Raman TR (2007). Conservation biogeography in North-East India: hierarchical analysis of cross-taxon distributiont congruence. Diversity and Distributions 13(1):53-65.

Rodriguez A, Perestelo F, Camicero A, Regalado V, Perez R, G de la Fuente, Falcon MA (1996). Degradation of natural lignin and lignocellulosic substrates by soil-inhabiting fungi imperfecti. FEMS Microbiology Ecology 21(3):213-219.

Sharma G, Pandey RR (2010). Influence of culture media on growth, colony character and sporulation of fungi isolated from decaying vegetable wastes. Journal of Yeast and Fungal Research 1(8): 157-164.

Sharma G, Pandey RR (2012). Diversity of microfungi in decaying vegetable wastes in Manipur, North-East India. Indian Phytopathology 65(2):170-176.

Sharma G, Pandey RR, Singh MS (2011). Microfungi associated with surface soil and decaying leaf litter of Quercus serrata in a subtropical natural Oak forest and managed plantation in Northeastern India. African Journal of Microbiology Research 5(7):777-787.

Suthur SS, Watts J, Sandhu M, Rana S, Kanwal A, Gupta D, Meena MS (2005). Vermicomposting of kitchen waste by using Essenia foetida (SAVIGNY). Asian J Microbiol Biotech Environ Sci 7:541-544.

Watanabe T (2002). Pictorial atlas of soil and seed fungi: morphologies of cultured fungi and key to species. CRC Press.

l

